\title{
On the Ideal Picture of Cultural Trade
}

\author{
Zou Bo $^{1^{*}} \quad$ Liu Jianhua ${ }^{2}$ \\ ${ }^{1}$ Jiangxi science and technology academy dean's Office Nanchang 330098, China; ${ }^{2}$ National Cultural \\ Industry Research Center of Yunnan University Kunming 650091 China \\ (zoubo9612@163.com, LJH751208@126.com)
}

\begin{abstract}
Based on the appropriate point of integration of nation-state main cultural trade objects , cultural trade picture should be natural: the dynamic mechanism of the trade is the value of recognition rather than the industrial division of labor, and the constrainted mechanism of trade walks in the market and nonmarket factors. Moreover, the production mechanism is the introduction of both tangible and intangible product exported or abandoned, while the trade and consumption mechanism is throughout the mixed procession of the constrained powered production and other sectors.
\end{abstract}

Keywords: Cultural Trade, The Main Object, Ideal Picture

\section{Introduction}

The Real refers to the specific situation of things presented necessarily the objective laws of the development of things which is not subject to the will of people. Ought objective facts, in essence, is a subjective concept, denying the existing state of the object from the perspective of the main , from the point view of the main which needs to evaluate the requirements of the object , and to eliminate or change those things need not conforming with the main object to obtain reasonable principal sense. Ought picture is not purely a subjective concept. It is also objective, and the subject and the object on the double meaning of the awareness and practice to achieve a specific unity which should abandon those empty imagination about objective facts " How is gallop argument" as the concept of subjectivity ought to understand the dialectical unity of the object of the law and the needs of the body . The object of the law is the objective prerequisites we ought to. The main needing is the main basis we ought to be on. In reality, first, this needs to be linked to the possibilities offered by the law of the object and needed to be compatible with the actual capacity of the main. This is the awareness of needing of the body itself and intermediary between the host-guest system we ought and the intermediary system which includes three subsystems: tools, languages, and symbols. Social relation tool system has decisive significance, because it provides the main practical and cognitive ability, which also provides objective laws into the manner and extent of the person's field of activity, that is the awareness and the use of the actual level of objective laws

Mainly for cultural trade, the main trade relations in the country, and the object of this process is cultural trade. In the understanding of cultural trade, real natural course and inexorable law on the basis of the needs and aspirations of the country has cultural trade as the main , however, in different countries due to different political, economic, cultural, cultural trade power constraints, the product, differs in the understanding of the mechanisms of circulation and consumption, and some even more different to understand the treatment of cultural products , for example, in some countries it is equivalent to industrial and commercial products, free trade advocate international culture, and some countries believe that cultural products, plays the national values and national identity, and the role of heritage, so to advocate in the international trade of cultural exception or multiculturalism.

Therefore bound to find an interchange, making it the platform of the reality of cultural trade in all countries, so that cultural products are able to achieve the reunification of the national the main and cultural trade object based on optimized production, circulation, distribution and consumption. The largest meet as many as possible of the main part of the common reality of the need to reduce trade disputes with the clash of civilizations, to build the United States and the United States and common harmonious world. In this paper, based on the actual situation in China, combined with the practical needs of the world body, following the objective laws of cultural trade, cultural trade being put to realistic operational picture should 
be natural.

\section{Dynamic Mechanism}

Dynamic mechanism, also known as enterprise incentive mechanism, is a more complex and critical enterprise operational mechanism and an important sub-mechanism, and is a more active mechanism with the nature of the power source. In general, the motivation is the pursuit of profit. The enterprise must have a dynamic mechanism of the pursuit of profit, and should have the right to reasonably use of the profits of the enterprise to transform the enterprise, for the development of enterprises. With this power and in order to make the various functional elements of enterprise, interactions and linkages are necessary to produce a strong economy. On the other hand, the main body of the enterprise is the employees, and it is reasonable to deploy staff to complete the function of personnel management, with better leadership functions, enterprises should be established, including the personnel system, labor system, the wage system, reward system, education system, personnel selection system, democratic management system, and political ideology system mechanisms of factors, including incentives. Being incentive for people, there are a lot of theoretical analysis and interpretation, such as content-based incentive theory. This theory focuses on incentive fees relating to specific research stimulating factors, of which the most famous is the theory of Maslow's hierarchy of needs (A Maslow). There are behavioral transformation of incentive theory that the purpose of incentives is to transform and corrective actions, such as Hyde (Heider) attribution theory and frustration theory. Another process type incentive theory which focuses on the motivation of the formation and behavior of target selection, in Feiluo $\mathrm{Mu}(\mathrm{V} \cdot \mathrm{H} \cdot$ Vroom) expectations early theory, puts that people are already aware of the benefits of specialization. The modern economy depends on the individual and specialization as well as enterprises and nations. In David Ricardo (David Ricardo), "Principles of Political Economy", which was the first to articulate and certificate the principle of comparative advantage, it is the basis of the Foreign Trade and Power. "Determinants of comparative advantage, as David Ricardo emphasizes the importance of labor productivity differences which are between countries, as long as the relative level of labor productivity is inconsistent, there is a trade motives."

On this basis, many scholars have made contributions to trade theory. Swedish economist (Heckscher), Heckscher and Ohlin (Ohlin) in each article discusses the relationship between the composition and the national resource factor endowments and trade patterns, and that the differences in factor endowments is the decision of the international division of labor and exchange of best important factor. The late 1970s, and the early 1980s, the U.S. economist Paul Krugman (Krugman) economists proposed "new trade theory" In addition to the differences of resources, economies of scale are also the cause of international trade and trade is another source of interest independent factors. Subsequently, the product life cycle theory and demand deciding trade theory, and Michael Porter's theory of are competitive advantage after the development of the country's competitive strategy theory of new classical economics of international trade theory, In essence, the logical starting point of these international trade theories is that labor purpose of the economic division of labor and specialization is the division of labor and specialization of the economy in order to pursue more profits. The pursuit of profit and business development power, the power of international trade is the pursuit of more profit, the origin of the power industry and the division of labor.

The impact of industrial and commercial products in international trade theory, some researchers also believe, is that foreign superiority trade with power is the industrial division of labor. This understanding and the spirit of the characteristics of the cultural products have a major conflict. Some countries such as France whose cultural products are output, attached on the values and ideologies that spread and being consumpt, which agrees that a huge negative impact on a country's nationally Therefore, these countries believe that the field of culture should not implement free trade, and the "cultural exception", the need for cultural trade restrictions and protection, to ensure that a certain percentage of their cultural products and the values of unity and the identity of the nation-state.

We know that the purpose of industrial products, due to the country's comparative advantage in the industrial division of labor based on trade, is to increase the welfare of all participants. Therefore, the results produced by the division of labor and specialization must be free trade, so that resources and products get better configuration, and the role of the market mechanism so that all benefits are better. For example, our own production, it takes 100 units of currency to get a product through trade, the same products, we only need to take 50 units of currency, we certainly support the industrial division of labor based on free trade.

Cultural trade, however, is different, and it is not a profit due to the result of the industrial division of labor, of course, is part of its power. 
But the power of the core is the dissemination of the culture of a nation-state value, concepts and ideas to make their own culture everywhere in the world, to make their own the values recognized by the people of other countries. This is not purely for profit, more than the cultural hegemony. Multiculturalism is the theoretical foundation of cultural trade, and like the colorful flowers in the park. The World Cultural Park is also flourishing multicultural. Production and subsistence may be essential for all human beings, and therefore, if a country does not, that it must be obtained through trade. However, the survival of cultural products is not human essential things, it is great material wealth abundant after the spiritual needs of a country's cultural consumers in another country is definitely not essential, such as Hollywood movies, a few million Chinese farmers are not necessarily to watch, but did not affect the period of daily life and the political, economic, cultural and social performance. We need a cultural trade, we need foreign cultural products, and more important is multicultural in the world, but the most fundamental is to get each of the recognition of each other's culture. In this way, in order to avoid misunderstandings and conflict, it can lead to the arrival of a harmonious world.

\section{The Production Mechanism}

Production of cultural knowledge can be divided into two parts: original production and replication. The former refers to the first cultural knowledge or endogenous production recorded for the first time, the latter the activity of replicating and coping the produced products. Replication is aimed at increasing the scale and scope of the production of cultural knowledge product. This is similar to the reproduction of material goods. Original production is divided into two stages in turn: the creation of tacit knowledge and the outside materialized expression of tacit knowledge. The operation of these stages shows a random cycle of running mechanism, which takes on a reciprocal process of spirits turned into matters - matters restored into spirit. Original production is either less economical or meaningless, while the copy of knowledge productions can achieve the growth of scale economy and scope economy.

Cultural knowledge production and general physical production both need to be put into a variety of factors. The main factors of the cultural knowledge production are human resources, knowledge products, laboratory equipment, equipment aids, and funding. Special operation mechanism of knowledge production is determining the main body of cultural knowledge production where innovative talents are the most important factor. Knowledge production is a creative process. It possesses the characters of a high degree of risks, continuity, uncertainty and complexity. Besides, it required financial support.

Marginal costs of cultural knowledge production were diminishing. The huge gains in cultural knowledge are generally achieved by large-scale replication of products and its sales. Because the cost of original production is huge, while copies cheap. Expanding the sales of cultural knowledge products will reduce the average cost of knowledge production and increase their profits on condition that the price remains unchanged. Low price mechanism for achieving the value of the products is the basis and premise of saving the costs of replication. Vice versa. Thus, a market mechanism is formed due to the interaction of these elements.

Traditional factors of cultural knowledge production's increasing mechanism of marginal returns generally follow the law of diminishing marginal returns. That is to say, in the case of technical conditions stay unchanged, simply increasing some factors of production, although the marginal product will increase, to a certain degree, the speed will become slower. Hence, marginal revenues gradually decreased. But when the cultural knowledge products showed an opposite law, things are different. First, if the marginal cost of knowledge production is decreased, marginal returns of its copies will be increased correspondingly. Second, when cultural knowledge products as a special factor of production put into the production process, marginal productivity will take on an increasing trend. Due to the character of knowledge products_completely non-competitive, special exclusive and non-exclusive and having strong positive external effects, knowledge products as the stock of knowledge and other consumer goods production of inputs function will show an increasing returns.

In the overseas cultural business, as the cultural products have two characteristicspublic products and culture discount, differences of returns between the main bodies are huge. Some countries, such as the United States, producers know these characteristics so well that they make a large number of copies, which will not cost them much, and sell it in a low price. Besides, American cultural products such as movies are good at reducing cultural differences, so as to make the cultural discount greatly reduced. Thus, scale economy is realized. But some countries where the initiative ability and replication technology are backward, the huge differences of cultural products increased the cultural discount, so the situation of competition is not good for them. 
Generally speaking, due to the dual attribution, cultural products must achieve its economic benefits as well as social benefits. In the real overseas cultural business, to realize economic benefits means to produce products according to the import countries' tastes, reduce cultural differences and the discount in order to sell the products at a higher price. At same time, it requires the advanced replication technology, especially digital technology, which can replicate numerous products with high fidelity, thereby reducing the marginal cost and increasing the marginal benefit to gain profits. The realization of social benefits should be seen from two aspects. From the exporter's standpoint, it should maximize amount of sales, disseminate their traditional culture and promote universal human values, thoughts and ideas. From the importer's standpoint, on the basis of meeting the spiritual human needs of entertainment, cultural products are required to have a positive effect in spreading good values and ideas, influencing people's sentiments, advocating the values of truth, goodness and beauty to the whole world, rather than spreading selfishness, vulgar culture , bloody violence and chaos.

As far as China is concerned, in the cultural business, we should balance the input and output. Because the two can mutually reinforce each other's growth to form a dynamic equilibrium. As an advocator and promoter of multiculturalism, we are seeking common grounds while reserving differences between countries. To build a harmonious world, we are neither intended to submerge other countries' culture through massive cultural output, nor willing to find nowhere as a living place for our excellent traditional culture and mainstream political culture. China is not the hotbed for the culture of Hollywood and Disney, nor does the Korean culture or French culture. Under the premise of the dominance of our excellent traditional Chinese culture and the mainstream political culture, China should learn from the other countries' good spirits and culture, and become a paradise for developing multiculture.

So we need to work hard on the tangible and intangible output as for our cultural form. Intangible cultural products mainly refers to the copyright trade, which is based on the book copyright trade. It can be extended to other categories of cultural products such as films and television, arts and crafts, performing arts, and software copyright trade. Tangible cultural products/ services refers to video products, books, objects, painting and calligraphy, performing arts and dance, culture and tourism. Through a variety of strategy and tactics, such as to encourage creativity, to familiar with foreign production and consumption market, to produce more products with less cultural differences, and to promote large-scale export trade, the influence of Chinese culture can be increased and expanded, our soft power can be enhanced, not to say the maintenance of our cultural sovereignty and cultural security.

\section{Circulation and Consumption Mechanisms}

The economic knowledge highlights the importance of information and knowledge. Information has renewable consumption loss, non-polluting, and many other substances. Energy does not have the characteristics of information production and social life, and consciously engaged in the production, processing, transmission, storage and use of information activities to become major economic and social activities. The mainstream of information activities is information and knowledge production, processing, and exchanging. The information provided to the human knowledge and wisdom. Information has become an important resource in the social production and life, informational consumption is an important guarantee of social sustainability and the development of recycling economy.

Information Society following the consumption, such as housing, tourism, automobiles, information consumption will become the new hot spot. With the improvement of income levels, enhanced awareness of social information, the structure of consumption forward high level and the development of information consumer shift wealth of information goods on the market for informational consumption formation material basis. The social significance of knowledge and information consumption is reducing the risk of decision-making, you can narrow the digital divide, you can narrow the gap between rich and poor, can stimulate economic growth, can be replaced by resources, can generate social benefits. The York Ataman "the impact of information technology on the development of world politics, that the government is no longer a monopoly of information, informational consumption is driven by demand rather than supply-driven. The globalization of information as well as information consumer market globalization has led to the globalization of society as a whole.

Therefore, the circulation and consumption mechanisms actually internalized in various fields of foreign trade in culture studies. Our motivation mechanism, constraint mechanism and production mechanism, all imbued with the shadow of the circulation and consumption. 
Produced products, if you do not enter the circulation and consumption, it will become a waste, dissemination and value of outstanding cultural recognition is also out of the question; Whether industrial division of labor value recognized, they are caused by cultural trade, circulation and consumption of its premise is also no consumption, there is no circulation and no so-called power production and trade; precisely because of the circulation and consumption, in order to guarantee the normal and orderly operation, there must be some restraint mechanisms, including market and non-market.

\section{Conclusions}

Although the picture is designed from the main need of foreign trade in culture ought, but we need to understand the reality of cultural trade development course, and sort out the essence of cultural trade on the basis of objective laws, to find the object of the combination of the subject and culture of the nation-state trade point , scientific planning blueprint for the development of foreign trade in culture, and under the guidance of the macroeconomic strategy, with better cultural trade, to the effect that it meets different demands, and reduces trade disputes with the clash of civilizations.

\section{References}

[1] Li Kunwang, "international economics", Beijing, China, higher education press, 2009, on page 3.

[2] Wang bing, "Theory of the connotation and characteristics of the market mechanism", "journal of Agricultural Bank of China WuHan Management Cadre Institute in 2000 in the Third Stage, Page 6.

[3] WenYaQing "The Analysis Knowledge Production System", "Journal of HeBei Economic and Trade University in 2007, on Page 18. 